University of New Hampshire

University of New Hampshire Scholars' Repository

\title{
Light Field and Water Clarity Simulation of Natural Environments in Laboratory Conditions
}

\author{
Shachak Pe'eri \\ University of New Hampshire, Durham, shachak.peeri@unh.edu \\ Glenn T. Shwaery \\ University of New Hampshire, Durham
}

Follow this and additional works at: https://scholars.unh.edu/ccom

Part of the Oceanography and Atmospheric Sciences and Meteorology Commons

\section{Recommended Citation}

Shachak Pe'eri and Glenn Shwaery " Light field and water clarity simulation of natural environments in laboratory conditions ", Proc. SPIE 8372, Ocean Sensing and Monitoring IV, 83721 A (June 12, 2012); doi:10.1117/12.918695; http://dx.doi.org/10.1117/12.918695

This Conference Proceeding is brought to you for free and open access by the Center for Coastal and Ocean Mapping at University of New Hampshire Scholars' Repository. It has been accepted for inclusion in Center for Coastal and Ocean Mapping by an authorized administrator of University of New Hampshire Scholars' Repository. For more information, please contact Scholarly.Communication@unh.edu. 


\title{
Light field and water clarity simulation of natural environments in laboratory conditions
}

\author{
Shachak Pe'eri*1 ${ }^{1}$ and Glenn Shwaery ${ }^{2}$ \\ ${ }^{1}$ Center for Coastal and Ocean Mapping, University of New Hampshire, Durham, NH 03824 \\ ${ }^{2}$ College Engineering and Physical Science, University of New Hampshire, Durham, NH 03824
}

\begin{abstract}
Simulation of natural oceanic conditions in a laboratory setting is a challenging task, especially when that environment can be miles away. We present an attempt to replicate the solar radiation expected at different latitudes with varying water clarity conditions up to $30 \mathrm{~m}$ in depth using a $2.5 \mathrm{~m}$ deep engineering tank at the University of New Hampshire. The goals of the study were: 1) to configure an underwater light source that produced an irradiance spectrum similar to natural daylight with the sun at zenith and at $60^{\circ}$ under clear atmospheric conditions, and 2) to monitor water clarity as a function of depth. Irradiance was measured using a spectra-radiometer with a cosine receiver to analyze the output spectrum of submersed lamps as a function of distance. In addition, an underwater reflection method was developed to measure the diffuse attenuation coefficient in real time. Two water clarity types were characterized, clear waters representing deep, open-ocean conditions, and murky waters representing littoral environments. Results showed good correlation between the irradiance measured at $400 \mathrm{~nm}$ to $600 \mathrm{~nm}$ and the natural daylight spectrum at $3 \mathrm{~m}$ from the light source. This can be considered the water surface conditions reference. Using these methodologies in a controlled laboratory setting, we are able to replicate illumination and water conditions to study the physical, chemical and biological processes on natural and man-made objects and/or systems in simulated, varied geographic locations and environments.
\end{abstract}

Key words: Light attenuation, solar illumination, water clarity, simulation,

\section{INTRODUCTION}

In the natural environment, both biological and physicochemical conditions may vary widely with season or time of year, geographic location and water depth as examples. The re-creation of natural ocean conditions in a controlled, laboratory setting would allow researchers to develop and test ocean observing systems and instrumentation for the study of oceanic processes in a cost-effective manner without having to conduct open sea trials for basic studies. Increasingly, studies of these oceanic processes require the highly accurate measurement and/or control of a broad variety of environmental parameters. Two of the key optical parameters in natural ocean conditions are background illumination and water clarity. Background illumination is a function of the light source (typically solar), cloud conditions and watersurface conditions. Initially, the interaction between downwelling light from the light source and the water surface/air interface conditions affect the quality and quantity of light transmitted through the water column. Suspended particulates, dissolved matter and the absorptive qualities of the seawater itself modify the characteristics of the light at depth. The overall goal of our effort was to replicate background illumination and water clarity conditions for specific geographic locations at a given date and time. This proof of concept could then be expanded to a variety of marine environments given quantitative knowledge of the specific environmental parameters at a site of interest.

An example of a current application for such a need is environmental monitoring using remote sensing. Much of the animal and vegetative marine life is dependent on the sun light and the water clarity for survival. Current standard methods require in situ observations and sampling to monitor the habitats [1],[2]. In recent years there have been efforts in U.S. state and national organizations for the use of optic remote sensing as an alternative for the survey of large areas over short periods of time. Two examples of these efforts are eelgrass mapping in New England waters and coral habitat mapping in the tropical water of the U.S. Virgin Islands [3],[4]. A laboratory that can mimic these natural conditions can aid in preparation for ground truth efforts and allow the development of mapping procedures before a physical visit to the study site that can be hundreds of miles away from the investigator's laboratory.

Ocean Sensing and Monitoring IV, edited by Weilin Will Hou,

Robert Arnone, Proc. of SPIE Vol. 8372, 83721A @ 2012 SPIE

CCC code: $0277-786 X / 12 / \$ 18 \cdot$ doi: $10.1117 / 12.918695$

Proc. of SPIE Vol. $837283721 \mathrm{~A}-1$ 
The objectives of this study were: 1) to simulate illumination and water clarity conditions that approximate those of coastal and oceanic waters, and 2) identify the observable colors at depth during calm sea state conditions using an optical sensor. Conceptually, optical sensors are light detectors that provide an objective means of measuring the flow of radiant energy. They operate based on geometric, radiometric concepts that are the science of electromagnetic or radiant energy in natural waters [5]. By housing a radiant energy detector in a watertight assembly and channeling the direction of the photons arriving at the detector, the flow of radiant energy can be measured as a function of direction at any location within a body of water. In addition, the wavelength dependence and state of polarization of the light field can be measured by adding appropriate filters to the instrument. From such measurements, precise descriptions of radiative transfer in natural waters can be developed. Common radiometric quantities are defined by the International Association of Physical Sciences of the Ocean (IAPSO; [6]).

This paper describes the experimental setup and measurements that were conducted at the Center for Coastal and Ocean Mapping (CCOM) Ocean Engineering facility in the University of New Hampshire (UNH) wave and tow tanks. Solar illumination expected in different environments was mimicked using a lamp array with a solar radiation spectral output. A horizontally directed light field was created by the array and transmitted from the light wall along the horizontal axis of the tank. Underwater video cameras and spectrometers were used to record and calculate the radiometric properties of the light field. In addition, the optical properties of the aqueous environment in the wave tank were determined and used to describe the potential for detection of a submersed feature as a function of water clarity, the light field, and the depth of the feature itself.

\section{RADIOMETRY QUANTITIES}

The traditional measurements were visual using a Secchi disc, a black and white patterned circular disk, mounted on a pole or line and lowered slowly into the water. Secchi disc readings are obtained by an observer above the surface of the water who must look downward through the water and estimate the depth at which the pattern on the disk is no longer discernible [7]. Secchi disc measurements are dependent on the visual capabilities (e.g., contrast sensitivity) of the observer and the environmental conditions, such as illumination and the observer's angle of view with respect to the sun, where light may reflect from the water surface to the observer (sun glint). An alternative radiometric technique to measure water clarity is the use of underwater optical sensors such as spectrometers to measure the decrease of the downwelling irradiance $E_{d}(\lambda)$ as a function of depth. The downwelling irradiance is the magnitude of the radiance product that is the optic power of the sun's radiation that reaches the earth's surface. The light decay through the water column is an exponential function of the diffuse attenuation function $K(\lambda)$ and depth $z$ [5],[8] and is defined by:

$$
E_{d}(z ; \lambda)=E_{d}(0 ; \lambda) e^{-2 K(\lambda) \cdot z}
$$

where $E_{d}(0 ; \lambda)$ and $E_{d}(z ; \lambda)$ are the downwelling irradiances at the water surface.

For observing imagery collected by optical remote sensing (either airborne or satellite), the optical sensor collects the spectral radiance reflected back from the seafloor or water, $L(\lambda)$. According to equation [1], the challenge of remote sensing above water is the non-linear contribution from the water body to the signal received from the seafloor or from an object suspended in mid-water. The sunlight transmittance through the water column varies as a function of solar wavelength. The observed radiance in shallow waters can be expressed as [9],[10]:

$$
L_{o b s}=L_{b} e^{-2 K(\lambda) \cdot z}+L_{w}
$$

where $L_{o b s}$ is the radiance observed at the sensor's detector, $L_{b}$ is the radiance contribution from the bottom, and $L_{w}$ is the observed radiance over optically deep water with no bottom contribution. As a result, only a subset of the spectral range from the downwelling irradiance reaches the bottom and is reflected back to the observer. The wavelength of the spectral range is typically between $350 \mathrm{~nm}$ to $700 \mathrm{~nm}$, depending on the water clarity and depth [5],[8]. The water clarity is typically classified based on the spectral shape of the diffuse attenuation coefficient, known as Jerlov Curves (Figure 1). 


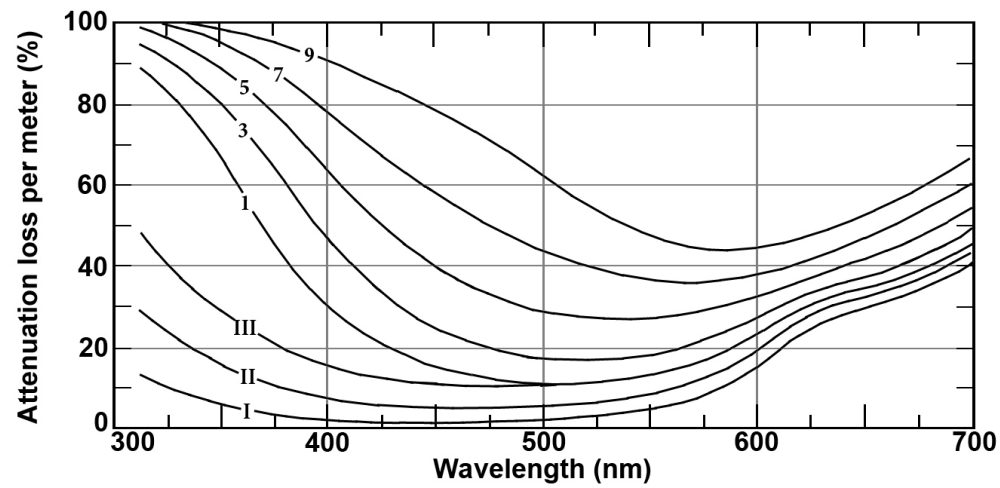

Figure 1. Percentage light loss per meter as a function of wavelength in oceanic (curves I to III) and coastal (curves 1 to 9) waters with varying degree of turbidity (from [8]).

\section{EXPERIMENTAL SETUP}

The challenge for us to replicate in a laboratory the solar radiation expected in waters located at different geographic locations around the world is the fact that there is no research facility with a $30 \mathrm{~m}$ deep water tank in the northern New England area. Also, it is not possible to conduct this simulation locally, off-shore. For example, the waters of the Gulf of Maine are considered as class 3 to 6 Jerlov coastal waters, depending on runoff and the tidal stage, whereas coastal Hawaiian waters (outside the ports) are closer to class I to II Jerlov oceanic waters. This challenge was met indoors in a laboratory by using the length $(36 \mathrm{~m})$ of a shallow, $2.5-\mathrm{m}$ deep tank at UNH (Figure 2). By configuring the horizontal axis of the tank to simulate the vertical depth component, we were able to study the effects of increasing depth on light transmittance and submerged object reflection (quality and quantity) under two environmental conditions of water clarity. In order for this configuration to be valid, we assumed that the water clarity (diffuse attenuation) was uniform along the tank and that the study was simulating only aerial observation/measurements directed vertically into a very calm sea (glassy surface).

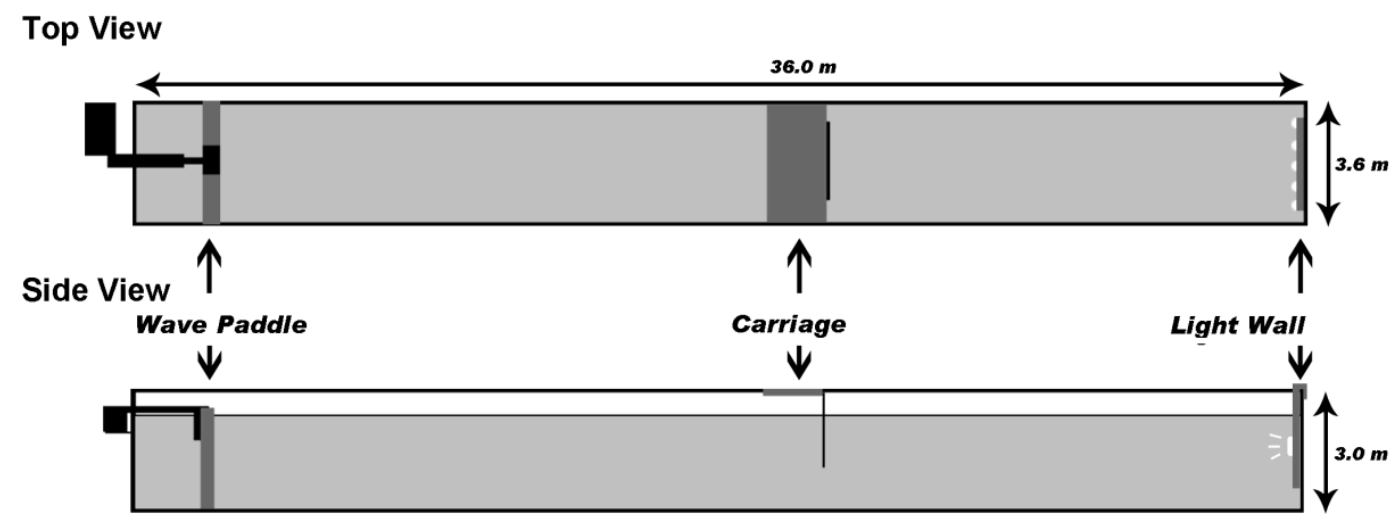

Figure 2. Schematic diagram of UNH's wave and tow tank (length units in meters)

\subsection{Illumination}

The spectral characteristics and intensity of solar illumination were mimicked using a light source array. The output of the array created a light field radiating along the horizontal axis of the tank. The selection of the light source was driven by the ability to produce an irradiance spectrum similar to natural daylight when the sun is at zenith and at $60^{\circ}$ under clear atmospheric conditions. In addition to the spectra produced from the lamps, there were other logistical considerations including configuration of underwater fixtures that would be waterproof and withstand lamp temperatures 
up to $700^{\circ} \mathrm{C}$, and finding a ballast that would produce the wattage required to ignite and support the power to operate the lamp. After reviewing product specifications from various manufacturers, an Eye Clean-Ace 400w MT400DL/BUD light bulb (source, EYE Lighting International Cleveland, OH, USA) with a M59 ballast (source, IAS products LTD., Vancouver, BC, Canada) was selected for the simulation. This lamp produces a "daylight" spectrum a black body radiating at $6500 \mathrm{~K}$. In addition to matching the sun spectral output, the light intensity per unit area was also similar to that measured at the ocean surface. A light wall cross-sectional area of $3.5 \times 1.0 \mathrm{~m}^{2}$ was mounted to the edge of the water tank with the lamps submerged approximately $0.9 \mathrm{~m}$ beneath the water surface.

Different configurations of the light wall were tested in order to produce a uniform irradiance and to define a virtual "water surface location" underwater. The "water surface location" is defined as the point along the lightpath at which the irradiance measurement approximates the spectral characteristics at the water surface under natural daylight conditions. The absolute irradiance was measured using a calibrated spectro-radiometer with a cosine receiver. The irradiance calculation for the spectral characteristics was conducted using a light wall composed of two lamps. The results were compared to published solar measurements [11]. The results show a good correlation between the measured irradiance ranging from $410 \mathrm{~nm}$ to $590 \mathrm{~nm}$ to natural daylight spectrum. A maximum correlation value of $\mathrm{r}^{2}=0.78$ was found at a distance of $3.5 \mathrm{~m}$ from the light wall to a zenith sun under clear atmosphere conditions, and a maximum correlation value of $\mathrm{r}^{2}=0.77$ was found at a distance of $4.0 \mathrm{~m}$ from the light wall to a sun at $60^{\circ}$ under clear atmospheric conditions (Figure 3).

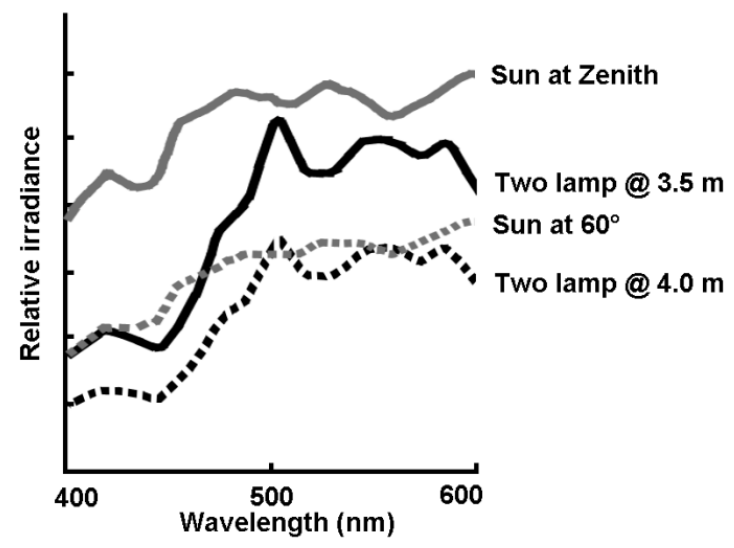

Figure 3. Irradiance measurements at $3.5 \mathrm{~m}$ and $4.0 \mathrm{~m}$ from the light wall (two lamps) versus irradiance measurements from a sun at zenith and a sun at $60^{\circ}$, respectively, under clear atmospheric conditions.

In addition to the spectral characteristics, the power intensity of the light wall was determined. In order to match the sunlight intensity, the light wall was configured with five lamps (Figure 4). A coefficient was also needed to scale irradiance output from the light wall to the typical total irradiance at sea level. The typical irradiance values for a zenith sun and a sun at $60^{\circ}$ under clear atmospheric conditions are $500 \mathrm{~W} / \mathrm{m}^{2}$ and $450 \mathrm{~W} / \mathrm{m}^{2}$, respectively.



Figure 4. Light wall configuration within the UNH wave tank (length units in meters). 


\subsection{Water conditions}

After defining the "water surface location", the light field and the water clarity conditions in the tank were defined. The light field was measured by expanding the spectral measurements up to $24 \mathrm{~m}$ from the light wall. The spectral measurements included: 1) irradiance measurements, where the spectrometer faced the light wall, 2) deep water radiance measurements, where the spectrometer faced away from the light wall and measured the light scattered in the water column, and 3) reflection measurements, where the spectrometer was oriented 120 degrees away from the light towards a white reference target that was illuminated by the light field. After normalizing the reflection measurements at the "water surface location" to $100 \%$, reflection measurements of the white reference target were used to monitor the attenuation of the light as a function of depth.

The measurements were conducted in two types of water clarity conditions, fresh, clear waters and still waters with some algal growth. In addition to the spectral imagery, underwater video imagery of the white reference was collected with the camera directed at the target from behind the light wall. The video imagery was used as a visual aid to confirm the water clarity calculations. In the case of the clear waters, the white reference was observed clearly at a distance of $24 \mathrm{~m}$. However, the white reference was barely visible at a distance of $18 \mathrm{~m}$ in the more turbid environment. The light field in both water cases showed an exponential decay following Beer's law. In the far-field (deep waters), the dominant spectral range in the clear water case was from $385 \mathrm{~nm}$ to $580 \mathrm{~nm}$, whereas, the far-field dominant spectral range in the turbid water case was from $460 \mathrm{~nm}$ to $590 \mathrm{~nm}$ (Figure 5). The diffuse attenuation coefficient was calculated directly from the signal decay of the irradiance measurement and indirectly from the change of white reference reflectance. Both calculations of the diffuse attenuation coefficient showed that the clear waters are Jerlov oceanic waters Case II, and the still waters area a Jerlov coastal waters Case 3 (Figure 6).

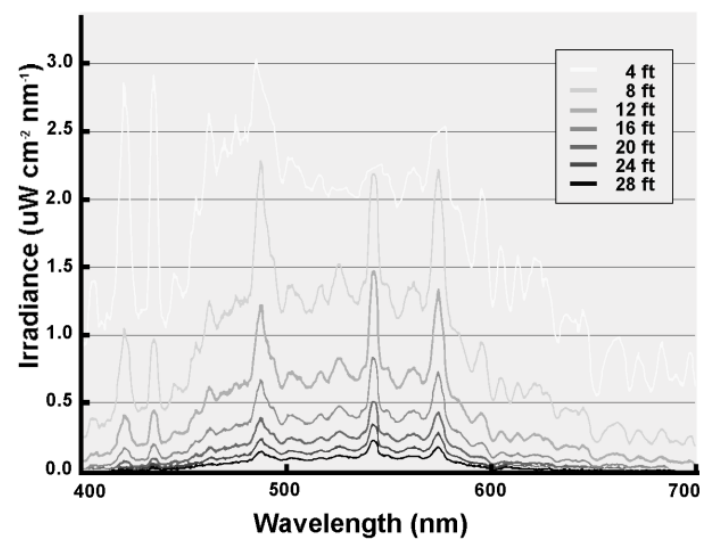

Figure 5. Irradiance measurements of still, murky waters as a function of distance (ft).

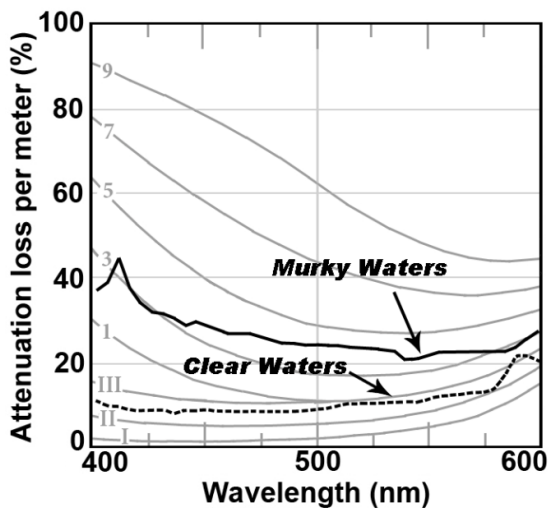

Figure 6. Diffuse attenuation coefficient plot of the UNH laboratory tank environment calculated from the irradiance measurements overlaid on the Jerlov plots. 


\section{DISCUSSION}

\subsection{Photosynthetic Available Radiation}

The wavelength of the spectral range is typically between $350 \mathrm{~nm}$ to $700 \mathrm{~nm}$, depending on the water clarity and depth [5],[8].We were able to simulate the solar spectrum in the blue-green regions $(410 \mathrm{~nm}$ to $590 \mathrm{~nm})$ in laboratory conditions, where the length of the water tank was used to simulate depth. However, the "water surface location" is a few meters away from the light wall in order to replicate the majority of the solar spectrum that is a product of the spectral output of the lamps and the optical properties of the water. The attenuation loss of the light in the red wavelengths per meter is $50 \%$, which is much larger than that in the blue and green wavelengths at approximately $10 \%$ (Figure 1). As a result, solar characteristics of the red region $(600 \mathrm{~nm}$ to $700 \mathrm{~nm})$ cannot be reproduced at the "water surface location" position. In the case of clear waters, the spectral characteristics of the red wavelengths do not match the solar spectrum (correlation values of 0.31 to 0.55 ) at the "water surface position" and the irradiance measurements are at the background noise level (no signal) at $6.0 \mathrm{~m}$ from the light wall.

For applications of remote sensing, one important, quantifiable property of the environment is photosynthetic available radiation (PAR). PAR is a broad band property that represents an integration of the radiation from $400 \mathrm{~nm}$ to $700 \mathrm{~nm}$. The PAR is relevant in studies of phytoplankton ecology as a means to monitor potential chlorophyll activity. In order to achieve a spectrum that is similar to the solar spectrum in the red wavelengths in a laboratory setting, the "water surface position" must be close to the light array. This would require two sets of spectral measurements for PAR observations, one for the red range and one for the blue-green range. Another option for achieving a full spectrum to include the red wavelengths is the use of different high intensity lamps. However, such lamps require a unique socket (G9.5 or G22) and high power ballasts that can be very costly. The decision as to how to build the light field for approximation of the illumination field should therefore be driven by the research question and the available resources.

\subsection{Deep water applications}

In addition to the daylight configuration for simulating water illumination up to $30 \mathrm{~m}$ in depth, the experimental setup within this long tank can be used for other marine applications. For example, the light field requirements are different for underwater photography and marine exploration. In deep underwater photography, there is an interest in maintaining a color balance among the red, green and blue spectral ranges. In this example, the requirement is to find a suitable light source for a diver or underwater vehicle to produce a specific light field within a certain range or focus distance from the object, rather than calculating the light field for a given spectrum. Examples of halogen and LED light sources that produce different spectral outputs are presented in Figure 7.

The configuration of the light wall allows easy replacement of lamps or using different combinations of lamps that are already in an underwater fixture. In addition, each lamp can be oriented individually to create a desired illumination pattern. A variety of targets can be positioned along the tank up to a distance of $30 \mathrm{~m}$. Subsequently, the light field and the reflectance of each target can be measured using the detector unit (spectrometer and the underwater video camera).

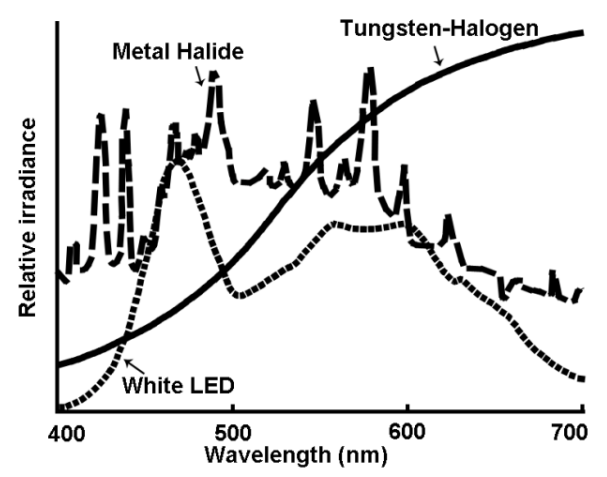

Figure 7. Irradiance plots of artificial light sources: tungsten-halogen light at $3000 \mathrm{~K}$, LED light at $7000 \mathrm{~K}$, and a metal halide at $6500 \mathrm{~K}$. 


\section{CONCLUSIONS}

In this study, natural ocean conditions of illumination in the blue-green region of the visible spectrum and variation in water clarity were re-created in a laboratory setting. The experiment was conducted in the UNH Ocean Engineering facilities. The first goal of the study was to simulate underwater conditions up to $30 \mathrm{~m}$ with natural daylight illumination. The two illumination conditions were a sun at zenith and a sun at 60 degrees with clear sky conditions in both cases. In addition, the light field and the diffuse attenuation of two different water clarity conditions were investigated. The second goal was to estimate the effective colors and brightness of a underwater target. Radiometric calculations were done to simulate the results for an optic sensor. The calculations assumed that the sensor/operator is looking down from an airborne platform located above the water surface at very calm sea state conditions.

The solar illumination was simulated using a light source array composed of Eye Clean-Ace 400w MT400DL/BUD light bulb. Different configurations of the light wall were tested in order to produce a uniform irradiance and to define a virtual "water surface location" underwater. The "water surface location" was identified based on correlation tests between the irradiance measurements along the light field and the reported natural daylight spectrum ranging from 410 $\mathrm{nm}$ to $590 \mathrm{~nm}$. Also, the light field and the water clarity conditions in tank were characterized. The diffuse attenuation coefficient was calculated directly from the signal decay of the irradiance measurement and indirectly from the change in reflection of the white reference target. Both calculations of the diffuse attenuation coefficient showed that the clear waters are Jerlov oceanic waters Case II and the murky waters are Jerlov coastal waters Case 3.

The experiment design has proven to simulate the solar spectrum in the blue-green regions ( $410 \mathrm{~nm}$ to $590 \mathrm{~nm})$ at clear sky conditions for of the visible light spectrum. The experimental setup is modular and can be used for other marine applications. The configuration of the light wall allows easy replacements of lamps in underwater fixtures by lighting sources that produce spectral outputs other than natural daylight. In addition, each lamp can be positioned and oriented to produce a desired illumination pattern. The experimental setup can be designed for remote sensing studies that focus on environmental monitoring or can be used for other marine applications, such as underwater photography and marine exploration.

\section{ACKNOWLEDGEMENTS}

The authors would like to thank Jacob Chamberlain and Nicholas Parrillo for their technical assistance during the work performed.

\section{REFERENCES}

[1] Morrison, J., T. Gregory, S. Pe'eri, W. McDowell, and P. Trowbridge, "Using Moored Arrays and Hyperspectral Aerial Imagery to Develop Nutrient Criteria for New Hampshire's Estuaries", The New Hampshire Estuaries Project report, September 30, 65 pp. (2008).

[2] Costa, B.M., L.J. Bauer, T.A. Battista, P.W. Mueller and M.E. Monaco, "Moderate-Depth Benthic Habitats of St. John, U.S. Virgin Islands", NOAA Tech. Memo., NOS NCCOS 105, Silver Spring, MD, 57 pp. (2009).

[3] Pe'eri, S., J. Morrison, F. Short, A. Mathieson, A. Brook, and P. Trowbridge, "Macroalgae and eelgrass mapping in Great Bay Estuary using AISA hyperspectral imagery", The New Hampshire Estuaries Project report, September $30,48 \mathrm{pp}(2008)$.

[4] Pe'eri, S., J. Guilford , I. Lundgren and T. Battista, "Buck Island, St. Croix - seafloor characterization using optic remote sensing", 12th JALBTCX Airborne Coastal Mapping \& Charting Technical Workshop, Baltimore, MD, June 21-22 (2011).

[5] Mobley, C. D., [Light and Water: Radiative transfer in neutral waters], Academic press, (CD version) (2004).

[6] Morel, A. and R.C. Smith, "Terminology and units in optical oceanography", Mar. Geod., 5(4), 335-349 (1982).

[7] Preisendorfer, R.W., [Hydrologic Optics], Pacific Mar. Environ. Lab/NOAA, Seattle, WA, 1206 pp. (1976).

[8] Jerlov, N.G., [Marine Optics], Elsevier Scientific Publication, New York, NY, 231 pp. (1976).

[9] Philpot, W. D., "Bathymetric Mapping with Passive, Multispectral Imagery", Appl. Opt., 28, p. 1569-1578 (1989).

[10] Maritorena, S., A. Morel, and Gentili, B, "Diffuse reflectance of oceanic shallow waters: Influence of water depth and bottom albedo", Limnol. Oceanogr., 39, 1689-1703 (1994).

[11] Robinson, N., [Solar radiation], Elsevier, Amsterdam, 347 pp. (1966). 